\title{
ПРИМЕНЕНИЕ СТАТИСТИЧЕСКИХ МЕТОДОВ В ИССЛЕДОВАНИИ ХИМИЧЕСКОГО СОСТАВА ДОННЫХ ОТЛОЖЕНИЙ ОЗЕРА ИМАНДРА
}

Мицуков А.С., Даувальтер В.А.

Институт проблем промышленной экологии Севера КНЦ РАН, Апатиты, Mitsukovaleks@gmail.com

\section{Аннотация}

Представлены возможности использования статистических методов (корреляционный и факторный анализ) для исследования химического состава донных отложений озера Имандра. Выявлены наиболее значимые факторы, влияющие на формирование химического состава донных отложений.

\section{Summary}

The possibilities of using statistical methods (correlation and factor analysis) to study the chemical composition of sediments of Lake Imandra are presented. The most significant factors influencing the formation of the chemical composition of sediments are identified.

\section{Введение}

В настоящее время остро стоит проблема антропогенного влияния на водные экосистемы. Происходит качественное истощение крупных водных объектов, как источников питьевого водоснабжения и биоресурсов. В Арктике одно из главных мест среди природных ресурсов занимают поверхностные воды. В Мурманской области расположено озеро Имандра, которое является источником питьевого водоснабжения, объектом рыболовства и имеет важное рекреационное значение, но в тоже время испытывает интенсивную антропогенную нагрузку, которая проявляется, в основном, в поступлении загрязняющих веществ в водоём, и последующее их накопление в донных отложениях, которые представляют собой своеобразный архив данных об изменениях, происходивших на водосборе и в самом водоёме [7]. Поэтому изучение влияния антропогенной деятельности на водные экосистемы является актуальной задачей, для выполнения которой могут быть использованы методы математической статистики, а именно факторный и корреляционный анализ. Цель работы заключается в исследовании химического состава донных отложений, с применением методов математической статистики.

\section{Материалы и методы}

Имандра - одно из крупнейших озер Заполярья - расположено на крайнем северо-западе Европейской территории России, в тектонической депрессии, которая делит Мурманскую область на две части: материковую и полуостровную. Озеро состоит из трёх обособленных плёсов: Большая, Йокостровская и Бабинская Имандры, которые соединяются между собой узкими проливами - салмами [1]. 
Образцы донных отложений (ДО) отбирались на 12 станциях (рис. 1) оз. Имандра сотрудниками Института проблем промышленной экологии Севера (ИППЭС) Кольского научного центра РАН, отборником колонок открытого гравитационного типа, разработанного Скогхеймом [14], сделанным из плексигласа (внутренний диаметр 44 мм), с автоматически закрывающейся диафрагмой. Колонки ДО были разделены на слои по 1 см, помещены в предварительно вымытую кислотой полиэтиленовую посуду и отправлены в лабораторию для анализа. Первичная обработка проб ДО (высушивание, определение влажности, прокаливание и определение потерь при прокаливании), определение содержания металлов ( $\mathrm{Ni}, \mathrm{Cu}, \mathrm{Co}, \mathrm{Zn}, \mathrm{Cd}, \mathrm{Pb}, \mathrm{Hg}, \mathrm{Mn}, \mathrm{Fe}$, $\mathrm{Ca}, \mathrm{Mg}, \mathrm{Na}, \mathrm{K}, \mathrm{Al}$ ) проводились в лабораториях ИППЭС [2]. Длина колонок ДО при исследовании оз. Имандра была, как правило, в диапазоне 17-25 см, следовательно, можно предположить, что в нижних слоях отобранных колонок ДО должны быть зафиксированы природные фоновые содержания элементов [3, 4].

Для определения влияния тех или иных факторов, на формирование химического состава ДО исследуемых станций отбора проб, для каждого из плёсов оз. Имандра были проведены корреляционный и факторный анализы с использованием пакета Statistica (Version 10.0). Значения считались достоверными при $\mathrm{p}<0.05$. При проведении данных анализов не учитывались результаты по ДО станции F-11 (губа Зашеечная) плёса Йокостровская Имандра, так как, скорее всего, в месте отбора ДО были перемешаны, как было отмечено в предыдущих работах [7], и станции I-11 (губа Белая) плёса Большая Имандра, так как при отборе колонки не были получены фоновые слои ДО, по причине высокой скорости осадконакопления в данном месте акватории.

\section{Результаты и обсуждение}

Разнообразие химического состава вод притоков, разная антропогенная нагрузка и изолированность плёсов относительно друг друга обуславливают сильные различия в химическом составе ДО оз. Имандра [1], которые формируются преимущественно из минеральных частиц, поступающих с водосборной площади $[9,10]$.

На территории водосбора оз. Имандра располагаются предприятия горнодобывающей промышленности (комбинат по добыче и переработке апатит-нефелиновых руд - АО «Апатит»), металлургической промышленности (медно-никелевое плавильное производство - Мончегорская промышленная площадка АО «Кольская ГМК»), железорудное производство (АО «Олкон»), энергетический комплекс (Кольская атомная электростанция, с прямоточной системой охлаждения), Апатитская ТЭЦ, каскад Нивских ГЭС), а также муниципальные стоки городов, в которых проживает более 150 тысяч человек. По берегам озера протянулись железная и автомобильная федеральные дороги [11]. На формирование химического состава ДО оказывает влияние множество факторов, среди которых, значительную роль играют техногенные. С помощью факторного анализа удалось выявить 


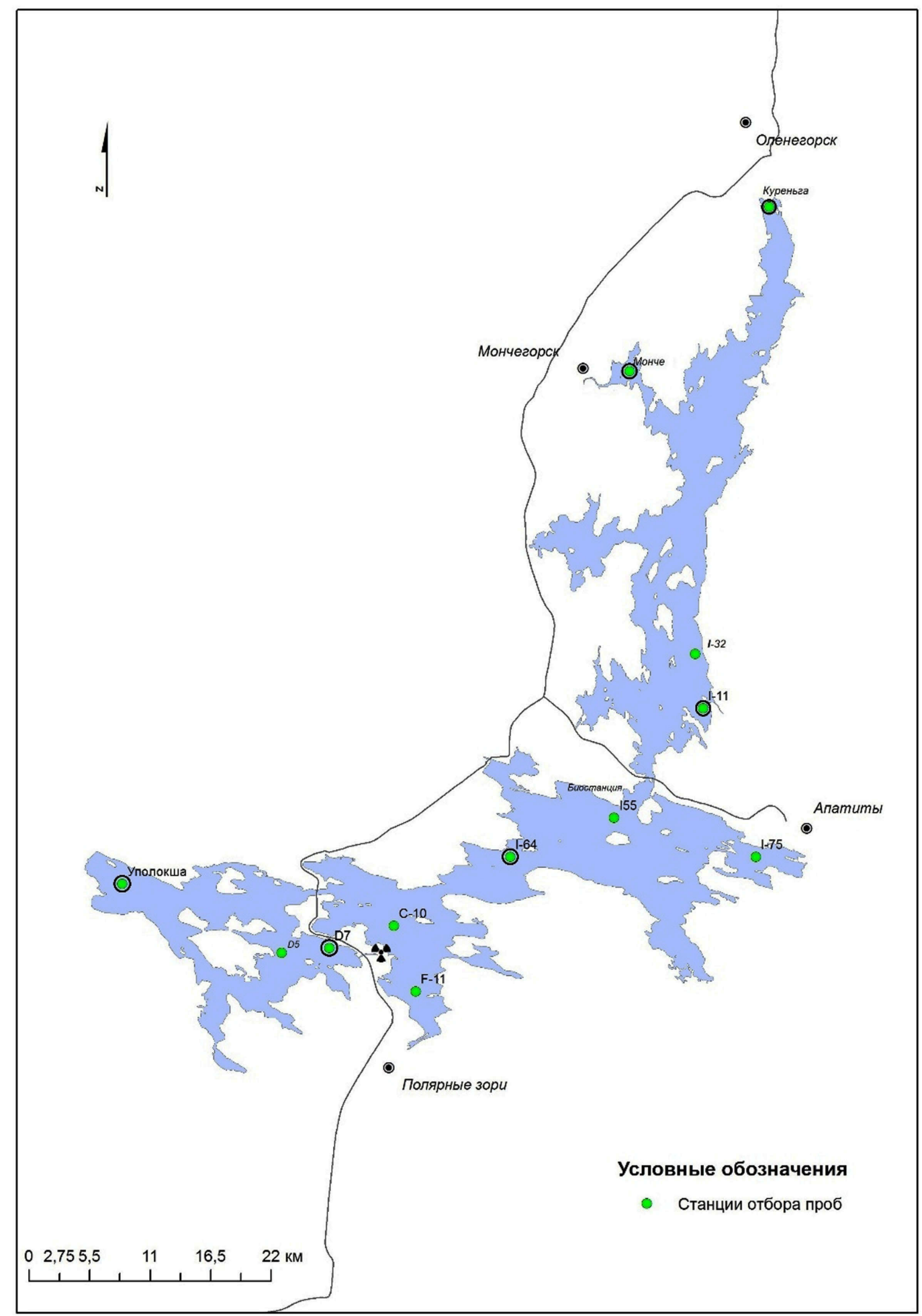

Рис. 1. Схема отбора проб донных отложений на озере Имандра.

три основных фактора определяющих формирование химического состава ДО плёсов оз. Имандра.

Самым загрязнённым считается плёс Большая Имандра, в котором за последние 60-70 лет произошли самые значительные преобразования химического состава ДО [11]. Первый фактор, доля которого от общей дисперсии составляет 45 \% (табл. 4), имеет положительные связи с $\mathrm{Cu}, \mathrm{Ni}, \mathrm{Zn}, \mathrm{Co}, \mathrm{Cd}$, $\mathrm{Pb}, \mathrm{Cr}$, As и $\mathrm{Mg}$, которые отрицательно коррелируют с глубиной слоя, что го- 
ворит об их накоплении по направлению к верхним слоям ДО. Таким образом, первый фактор тесно коррелирует с элементами, источником поступления которых в воду, а затем и ДО, вероятно, являются стоки предприятия АО «Кольская ГМК», расположенного на водосборе плёса Большая Имандра [1].

Второй фактор, вклад которого составляет 28 \%, отрицательно связан с распределением концентраций в толще ДО, таких элементов, как: $\mathrm{Sr}, \mathrm{Al}, \mathrm{P}$, $\mathrm{K}$, Са. Источником поступления данных элементов в большом количестве могут быть стоки предприятия АО «Апатит» и хозяйственно-бытовые стоки населённых пунктов, расположенных на водосборе плёса. Это предположение подтверждается тем, что в составе стоков предприятия АО «Апатит», в о3. Имандра, поступают, прежде всего элементы, содержащиеся собственно в минералах апатите и нефелине - Al, P, K, Ca, Na, а также сопутствующий им щёлочноземельный элемент $\mathrm{Sr}$ [8].

Менее значимый третий фактор, на который приходится 10 \% общей дисперсии, отрицательно связан с распределением Mn и Fe в толще ДО. Эти элементы чутко реагируют на изменения физико-химических условий в толще воды и ДО, в первую очередь окислительно-восстановительной обстановки $[5,6]$. Поступление в данную акваторию Mn и Fe в составе сточных вод АО «Олкон» продолжалось вплоть до 1975 года, и несмотря на введение системы замкнутого водоснабжения, в том или ином объёме эти элементы продолжают поступать в северную часть плёса Большая Имандра - г. Куреньга [1]. Исходя из этого, можно предположить, что третий фактор отражает деятельность Оленегорского комбината и геохимические условия, влияющие на формирование химического состава ДО.

Результаты корреляционного анализа (табл. 1) показали, что в ДО Большой Имандры отмечены две группы элементов, тесно коррелирующих между собой и имеющих незначительные корреляционные связи с остальными исследуемыми элементами. Первая группа элементов $\mathrm{Cu}, \mathrm{Ni}, \mathrm{Co}, \mathrm{Cd}, \mathrm{Pb}$ характеризуется наибольшими положительными корреляционными связями $(\mathrm{r}>0.9)$ между собой, также в эту группу входит $\mathrm{Zn}$, коэффициент корреляции r которого с перечисленными элементами составляет от 0.87 до 0.89. Это может говорить о том, что их поступление в Большую Имандру происходит вместе, и скорее всего, их источником являются сточные воды промышленных предприятий, расположенных на водосборе, в состав стоков которых входят $\mathrm{Ni}, \mathrm{Cu}, \mathrm{Co}, \mathrm{Zn}$ и другие загрязняющие вещества [1], а также выбросы в атмосферный воздух и поступление этих элементов вместе с поверхностным стоком. Вторая группа элементов Sr, Al, P, K, Са характеризуется незначительными корреляционными связями со всеми исследуемыми тяжелыми металлами (ТМ), но они хорошо коррелируют между собой (r>0.8), также значимая связь, для этих элементов, установлена с Na. Наибольшие коэффициенты корреляции между элементами зафиксированы для $\mathrm{Sr}, \mathrm{P}, \mathrm{Ca}(\mathrm{r}=0.97)$, что говорит о возможном совместном поступлении этих элементов в акваторию плёса Большая Имандра. 
Менее загрязнённым считается плёс Йокостровская Имандра, он соединяется Йокостровским проливом с плёсом Большая Имандра, из которого посредством стока, поступают загрязняющие вещества, где они осаждаются на дно водоёма и аккумулируются в ДО. Загрязняющие вещества в Йокостровскую Имандру также могут поступать путём стока с площади водосбора.

С помощью факторного анализа выявлены три фактора влияющие на формирование химического состава ДО Йокостровской Имандры (табл. 4). Первый фактор, вес которого составляет 46\%, объединяет группу тяжёлых металлов - $\mathrm{Cu}, \mathrm{Ni}, \mathrm{Zn}, \mathrm{Co}, \mathrm{Hg}$, а также $\mathrm{Sr}, \mathrm{Al}, \mathrm{P}$, источником которых, могут являться выбросы и сбросы загрязняющих веществ промышленных предприятий, таких как $\mathrm{AO}$ «Апатит», $\mathrm{AO}$ «Кольская ГМК», $\mathrm{AO}$ «Олкон», которые могут мигрировать в данную акваторию из Большой Имандры [13], поскольку Йокостровская Имандра является единственным местом, где происходит сток всего растворённого и взвешенного материала поступающего в оз. Имандра. Второй фактор, имеет вес в 23 \% и положительно коррелирует с $\mathrm{Cd}, \mathrm{Pb}$, As. Источником перечисленных элементов, также могут являться сбросы комбината АО «Кольская ГМК», но дополнительным источником данных элементов может быть автотранспорт, поскольку в отработанных газах двигателей внутреннего сгорания содержится $\mathrm{Pb}$, который присутствует в топливе, в качестве добавки (этилированный бензин). Третий фактор, вес которого составляет 14 \%, положительно коррелирует с Fe и $\mathrm{Mn}$. Как уже было отмечено выше, эти элементы очень отзывчивы на изменение физикохимических условий [6], а именно, окислительно-восстановительной обстановки, которое происходит на границе ДО и нижних слоёв водной толщи; более детально этот процесс описан в [5]. Таким образом, третий фактор может выражать влияние геохимических условий на формирование химического состава ДО плеса Йокостровская Имандра.

Корреляционный анализ (табл. 2) показал, что практически все рассматриваемые ТМ имеют значимые корреляции с глубиной слоя в ДО исследуемых станций данной акватории озера Имандра, что говорит об увеличении концентраций этих элементов по направлению к поверхности ДО. Fе и $\mathrm{Mn}$ значимо, положительно коррелируют между собой $(\mathrm{r}=0.71)$, что говорит о схожести их распределения в толще ДО Йокостровской Имандры.

Относительно незагрязнённым считается плёс Бабинская Имандра, по причине его удалённости от промышленных предприятий - источников поступления загрязняющих веществ в составе сточных вод $[11,12]$, но, несмотря на это, данная акватория подвержена влиянию атмосферных выбросов, а также влиянию хозяйственно-бытовых стоков населённых пунктов и трансграничным переносам загрязняющих веществ из стран Западной Европы [7]. Вдобавок сюда поступают относительно более загрязнённые воды Йокостровской Имандры, в результате работы Кольской АЭС, которая использует воду для охлаждения энергетических установок, забирая её из акватории Йокостровской Имандры и сбрасывая в акваторию Бабинской Имандры [13]. 


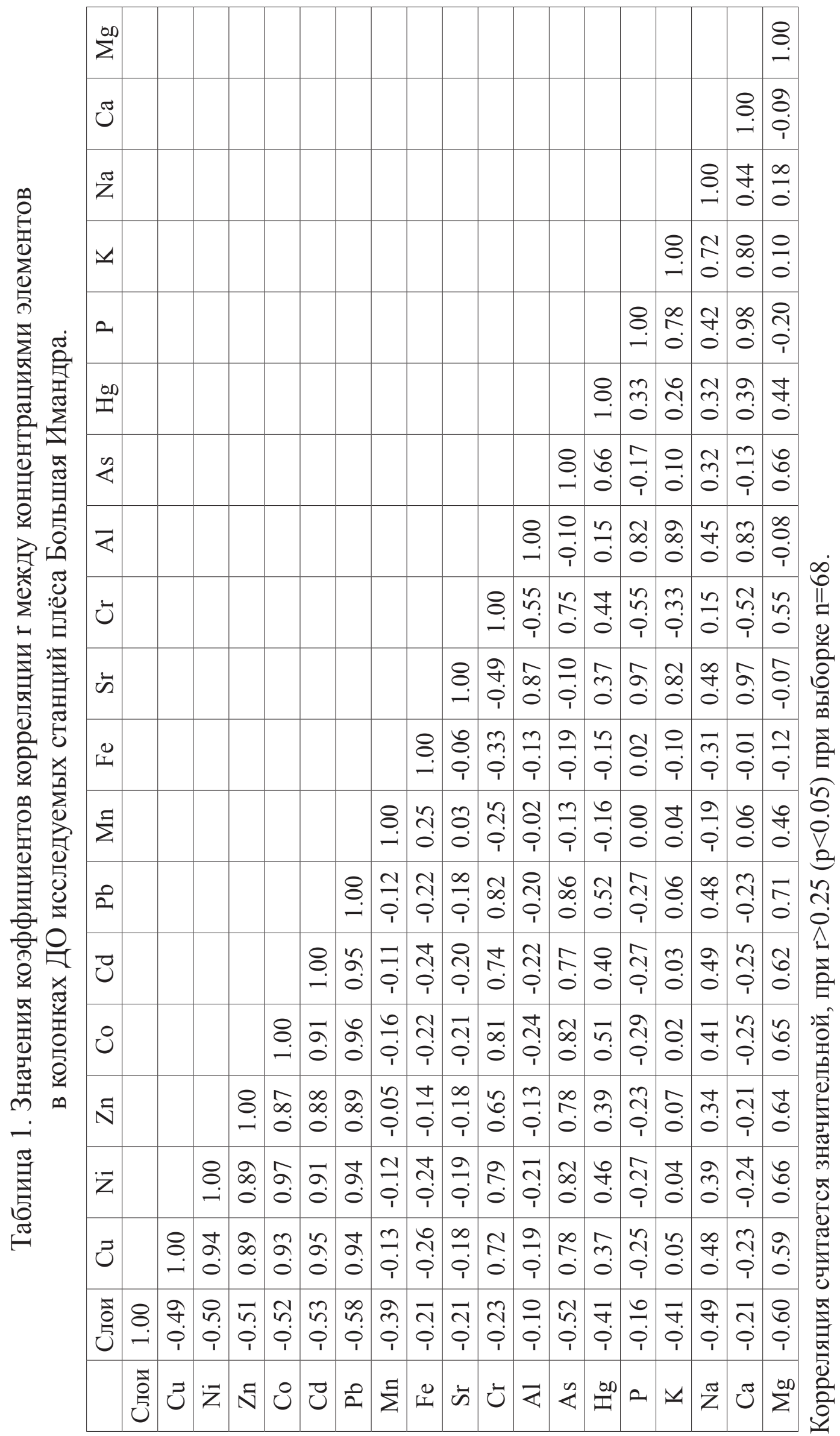




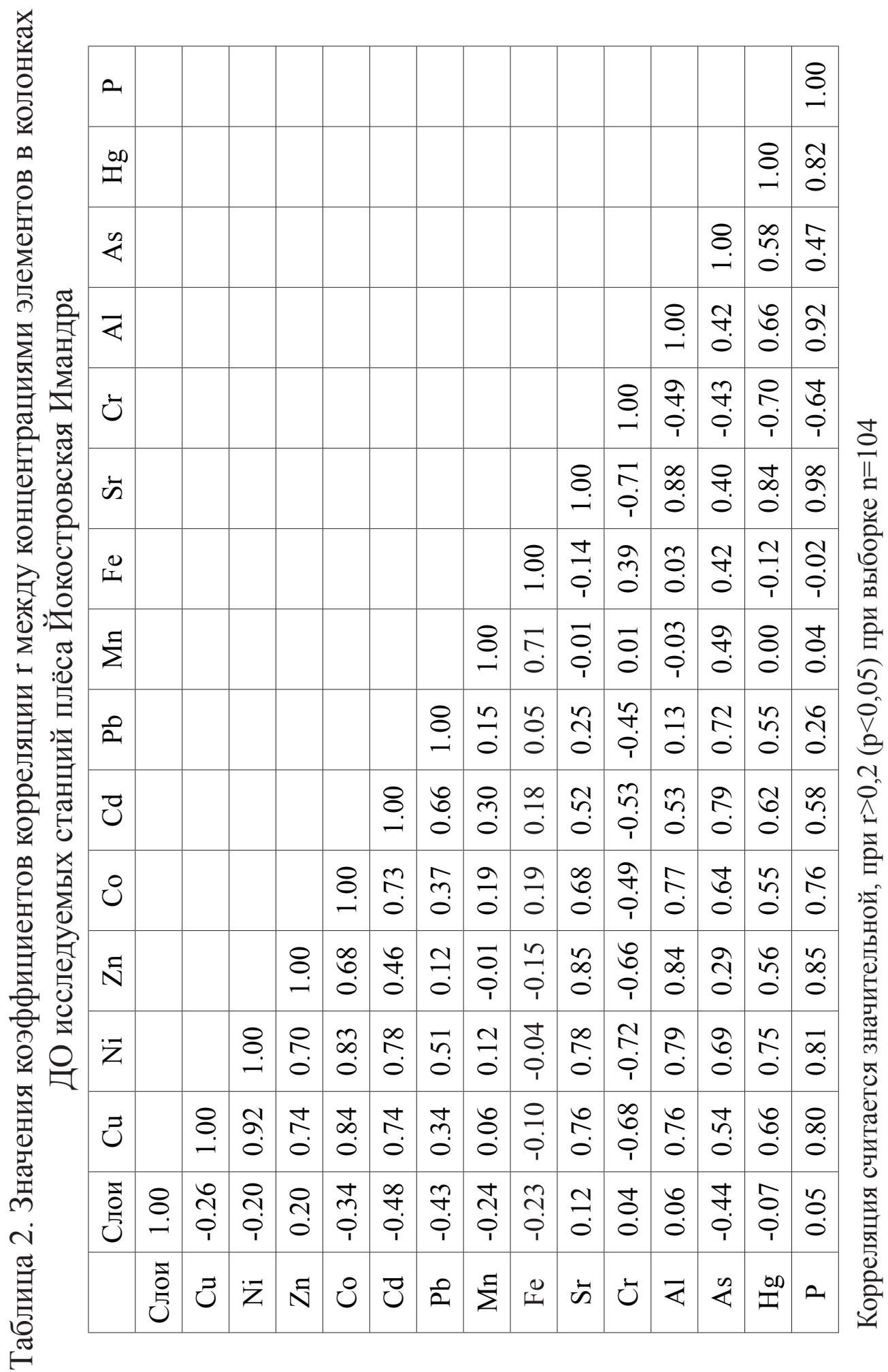




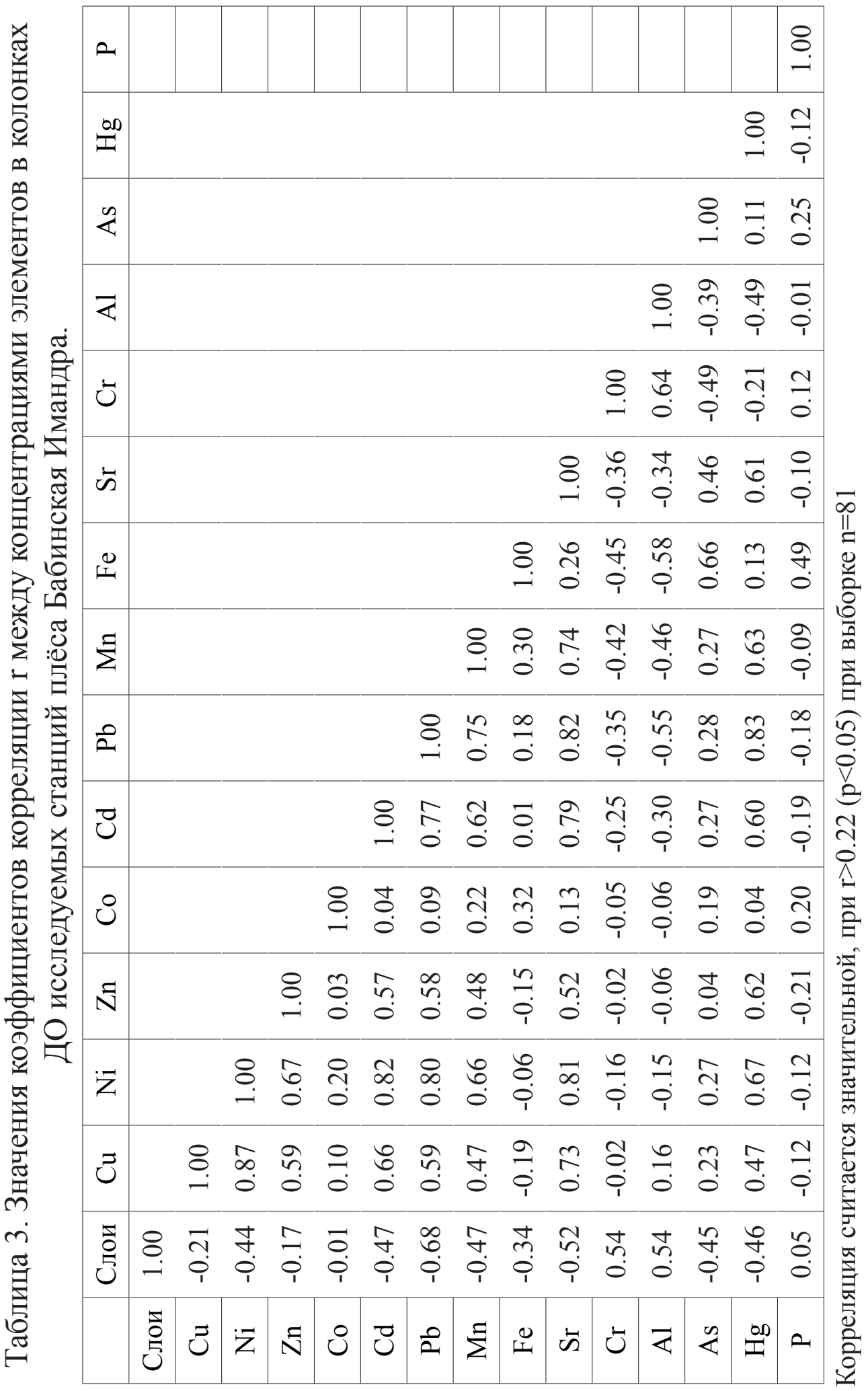




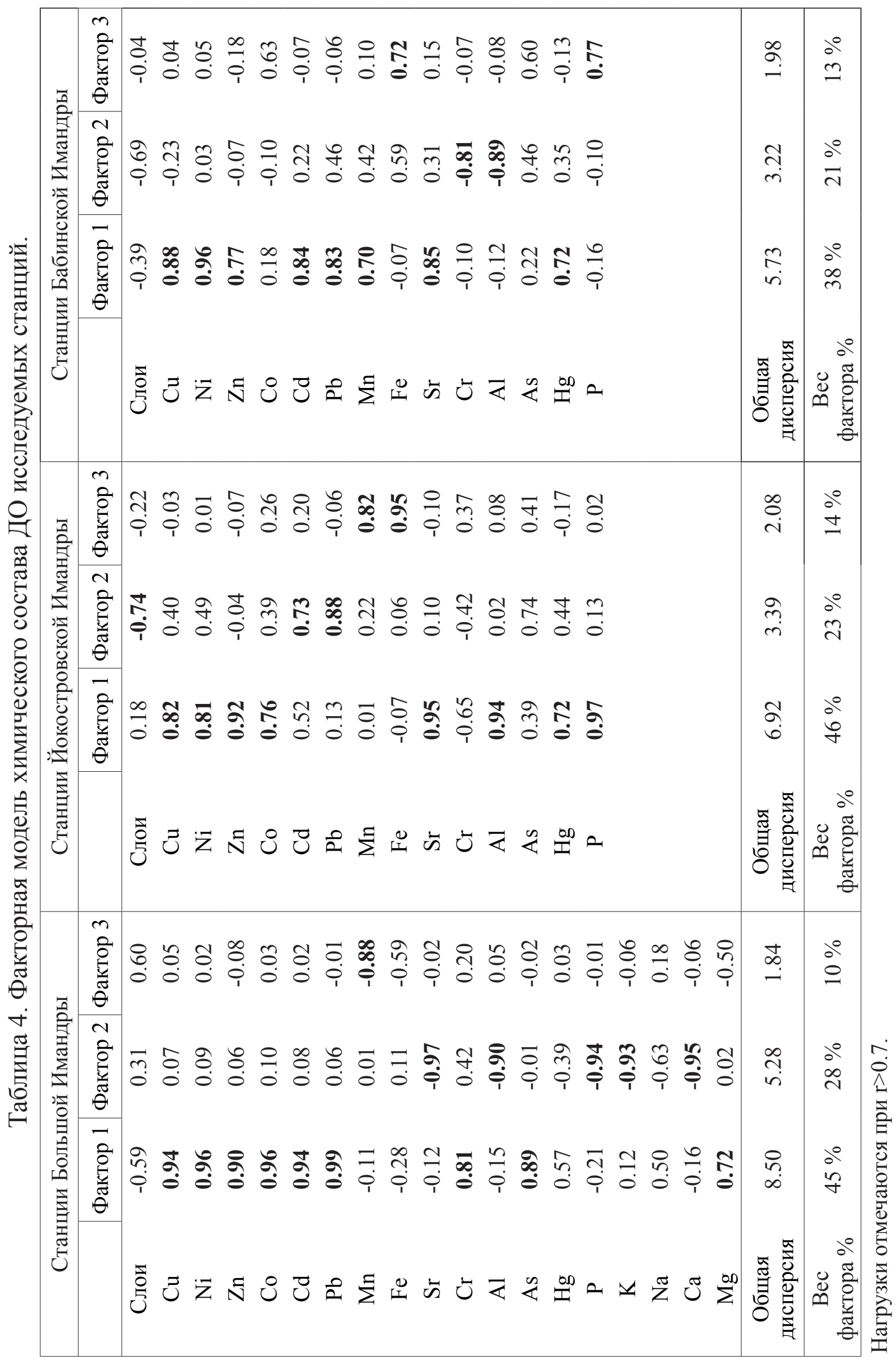


При проведении факторного анализа (табл. 4) были выявлены три фактора, воздействующие на формирование химического состава ДО Бабинской Имандры. Первый фактор, доля которого в общей дисперсии составляет $38 \%$, имеет положительные корреляционные связи с $\mathrm{Cu}, \mathrm{Ni}, \mathrm{Zn}, \mathrm{Cd}, \mathrm{Pb}$, $\mathrm{Mn}, \mathrm{Sr}, \mathrm{Hg}$. Вероятно, источником поступления этих элементов является аэротехногенное загрязнение выбросами предприятий региона, сток и поступление их с площади водосбора и трансграничный перенос глобальных загрязнителей из южных регионов.

Второй фактор, вклад которого в общую дисперсию равен 21 \%, объединяет такие элементы, как Cr, Al. Коэффициент корреляции между этими элементами равен 0.64 (табл. 3). Также эти элементы положительно коррелируют с глубиной слоя, что говорит об уменьшении, концентрации $\mathrm{Cr}$ и $\mathrm{Al}$ по направлению к поверхности ДО. В целом, полученные, при проведении корреляционного и факторного анализа результаты для плёса Бабинская Имандра, соотносятся с ранее полученными в [7] результатами.

\section{Выводы}

Применение статистических методов в исследовании химического состава донных отложений позволило установить, что техногенные факторы, а именно, поступление загрязняющих веществ в составе стоков и выбросов промышленных предприятий, расположенных на водосборе, оказывают значительное воздействие на формирование химического состава донных отложений озера Имандра.

\section{Список литературы}

1. Моисеенко Т.И., Даувальтер В.А., Лукин А.А. и др. Антропогенные модификации экосистемы озера Имандра. М: Наука. 2002. 403 с.

2. Геоэкология донных отложений озер / В. А. Даувальтер. - Мурманск: Изд-во МГТУ. 2012. 242 с.

3. Даувальтер В.А. Оценка экологического состояния водоемов по химическому составу донных отложений // Геология, геохимия и экология Северозапада России. Мат. І межд. науч. конф. С-Пб. 2005. С. 94-96.

4. Даувальтер В.А. Донные отложения - источник информации для оценки экологического состояния водоемов и их водосборов // Мат. межд. науч.техн. конф. «Наука и образование». 2006. С. 830-834.

5. Даувальтер В.А., Ильяшук Б.П. Образование железо-марганцевых конкреций в донных отложениях озер Балтийского кристаллического щита // Труды III Ферсмановской научной сессии. 2006. С. 158-161.

6. Даувальтер В. А., Кашулин Н. А. Влажность донных отложений озера Имандра как маркер деятельности горно-перерабатывающей промышленности // Межд. науч-техн. конф. «Наука и образование». 2013а. С. 891-895. 7. Даувальтер В.А., Кашулин Н.А. Долговременные изменения химического состава донных отложений озера Имандра в зоне влияния стоков Кольской атомной электростанции // Труды КНЦ РАН. 2013б. № 3. С. 6-35. 
8. Даувальтер В.А., Кашулин Н.А. Влияние разработки апатитонефелиновых месторождений на химический состав донных отложений озера Имандра // Экологическая стратегия развития горнодобывающей отрасли, сборник докладов Всерос. науч-техн. конф. с участием иностр. специалистов. 2014. T. 1. С. 383-390.

9. Даувальтер В.А., Кашулин Н.А. Изменение концентраций никеля и меди в поверхностных слоях донных отложений оз. Имандра за последние полвека // Вестник МГТУ. 2015 а. С. 307-321.

10. Даувальтер В.А., Кашулин Н.А. Основные закономерности распределения тяжелых металлов в донных отложениях озер северо-западной части Мурманской области и приграничной территории сопредельных стран // Вестник КНЦ РАН. 2015 б. С. 101-112.

11. Даувальтер В. А., Кашулин Н. А. Оценка экологического состояния озера Имандра по результатам исследований химического состава донных отложений // Экологические проблемы северных регионов и пути их решения. Апатиты: Изд-во КНЦ РАН. 2016. С. 181-185.

12. Даувальтер В.А., Кашулин Н.А., Денисов Д.Б и др. Комплексная оценка экологического состояния о3. Имандра по результатам гидробиологических и гидрохимических исследований // Матер. VII науч. сессии Геол. ин-та и IV конф. Ассоц. науч. обществ Мурманской области. 2016. С. 21-31.

13. Денисов Д.Б. Современное состояние водорослевых сообществ планктона в зоне влияния Кольской АЭС (оз. Имандра) // Труды КНЦ РАН: прикладная экология Севера. 2013. Вып. 3. № 16. С. 68-94.

14. Skogheim O.K. Rapport fra Arungenprosjektet. Oslo. 1979. N. 2. P. 7. 